\title{
Language and landscape: a cross-linguistic perspective
}

\author{
Niclas Burenhult*, Stephen C. Levinson \\ Language and Cognition, Max Planck Institute for Psycholinguistics, P. O. Box 310, \\ 6500 AH Nijmegen, Netherlands
}

\begin{abstract}
This special issue is the outcome of collaborative work on the relationship between language and landscape, carried out in the Language and Cognition Group at the Max Planck Institute for Psycholinguistics. The contributions explore the linguistic categories of landscape terms and place names in nine genetically, typologically and geographically diverse languages, drawing on data from first-hand fieldwork. The present introductory article lays out the reasons why the domain of landscape is of central interest to the language sciences and beyond, and it outlines some of the major patterns that emerge from the cross-linguistic comparison which the papers invite. The data point to considerable variation within and across languages in how systems of landscape terms and place names are ontologised. This has important implications for practical applications from international law to modern navigation systems.

(c) 2007 Elsevier Ltd. All rights reserved.
\end{abstract}

Keywords: Geographical ontology; GIS; Landscape terms; Place names; Semantic domain; Semplates

\section{Introduction}

Many disciplines and specialist lines of research have been interested in human understandings of landscape, for example archaeology (Tilley, 1994), anthropology (Bender, 1993; Hirsch and O'Hanlon, 1995; Ellen and Fukui, 1996), psychology, philosophy and, of course, cognitive geography (Mark et al., 1999; Smith and Mark, 2001, 2003; Mark

\footnotetext{
* Corresponding author. Tel.: +31 243521 270; fax: +31 243521213.

E-mail address: Niclas.Burenhult@mpi.nl (N. Burenhult).
} 
and Turk, 2003a, 2004). It is perhaps less obvious why this topic might be of any significant interest to linguistics. But a moment's reflection reveals a domain with wide ramifications through the linguistic sciences: How are landscape features selected as nameable objects ('river', 'mountain', 'cliff')? Are there universal categories? What is the relation between landscape terms (common nouns) and place names (proper nouns)? How translatable are landscape terms across languages, and what ontological categories do they commit to? Do they form structured sets of terms, semantic fields, with possible grammatical reflexes?

In the first part of the introduction to this special issue, we therefore lay out some of the reasons why this proves to be a fascinating domain for linguists, while in the second part we outline some of the interesting features that emerge from the cross-linguistic comparisons which the papers in this volume invite. We hope this collection of articles, which presents data from nine diverse languages, will play a pioneering role in establishing this topic in sustained linguistic discussions.

\section{Landscape: an important but unexplored area of linguistics}

Landscape, or more generally 'environment', provides an interesting domain of human categorisation and labelling for a number of reasons. First, just as everyone has a body (see the special issue of this journal edited by Majid et al., 2006), every human inhabits a landscape, even if the nature of that is highly variable. Just like the body, parts and categories rely on a segmentation of what is, from a topological point of view, largely a continuous surface - the division into parts is to a great extent imposed by our categories. In both cases, too, there is a sense in which we inhabit them, and ecologies have a profound influence on how we live. (Unlike the body, of course, environments differ dramatically, and landscapes offer no private access to their inner workings; landscapes are also less 'jointed', so they may offer greater opportunity for diverse ontologies).

A second point is that landscape (if understood to include the cityscapes in which half of humanity now lives) provides the fundamental 'Immobilien' of our worlds ${ }^{1}$ : it furnishes us with large, (almost) immoveable entities and surfaces, with spatial and temporal constancy and three-dimensional complexity on a large scale. The landscape presents itself to the developing child as the backdrop for action, as a conceptual domain with its own spatial properties - one conceives of oneself as necessarily inside it, with the attendant puzzles of wayfinding and navigation (see Piaget and Inhelder, 1971). The Western mode of navigation, based on turns to the left or right, is adapted to dense systems of existing streets, roads and paths. Hunter-gatherers and others who live in less constructed landscapes tend to use non-egocentric systems of navigation, e.g., absolute abstract directions like north, south, east and west (Majid et al., 2004). These contrastive cognitive styles are reflected in language, which seems to play a causal role in inducing community-wide consensus for one style over the other - some languages do not even have directional terms for 'left' and 'right' (Levinson, 2003). In both kinds of wayfinding, though, landmarks play a crucial role - the essential Immobilien provided by our landscape cognition.

\footnotetext{
${ }^{1}$ The German term Immobilien for real estate captures some central properties of landscape features: their immobility and scale.
} 
Is landscape properly thought of as a semantic domain, like kinship, colour or folk biology? As always, one should let the language decide. Do the descriptive terms ('hill', 'lake', 'river' and the like) form a system, a set of contrastive terms, or a set that draws on shared rules of formation, or a set whose structure is unified by an underlying set of semantic parameters? Do the descriptive terms form a covert category, taking, e.g., special forms of a locative, dative or ablative marker (cf. sea-wards), or zero-marking of location or direction (cf. He went home)? For many languages (see the papers below), an argument can certainly be made that lexical subsystems exist in this conceptual field. Indeed, one of the discoveries arising from this collection is that this is a conceptual field where what we dub semplates are quite pervasive - semplates are semantic templates that structure a lexical set, often in covert ways (see Section 3.4 below).

If and when parts of the landscape domain function like semantic fields, they may do so in different ways. In principle there could be taxonomic (kind-of) relations between landscape terms, so that, e.g., a brook could be a small kind of stream, which could be a small kind of river. Alternatively, the relation could be partonymic (or meronymic), so that Berlin could be part of Brandenburg, or a park part of a city, or a bay part of the sea. In fact, judging from the papers in this volume, neither of these hierarchical schemes seem prominent in native conception or linguistic conceptualisation (with the partial exception of area terms, which may have partonymic conceptualisations). Leaving aside area terms, landscape terms for the most part seem to denote objects - very large, unmoveable objects, Immobilien in fact. In many cultures, landscape objects can be bought, sold, inherited and bequeathed in similar ways to chattels (Mobilien in German). But if landscape features are treated by languages just like objects, why think there might be any special linguistic science of landscape terms? One reason is that languages tend to treat landscape terms as systematically ambiguous between objects and places: in 'The forest is huge', the forest is an object, in 'The ruin is in the forest', the forest becomes a place, with special semantic and syntactic properties (Lyons, 1977, pp. 477ff). ${ }^{2}$ In English (and other European languages), one of the neat things that prepositions do is convert objects into places: if the table is an object, on the table is a place, and these are quite different ontological categories (Jackendoff, 1983; Landau and Jackendoff, 1993). Places can be freely introduced as locative adjuncts (He sang on top of the mountain), and they provide the grounding for spatial movement, freely collocating with special cases (e.g., Ablative, Allative) or spatial prepositions (into, onto, out of).

If places have a special ontology, landscape terms themselves make individual commitments to specific landscape entities. 'Mountain', 'cliff' and 'river' presume the existence of such things - they seem real enough that one might reasonably consider universal concepts here (Smith and Mark, 2001). But one of the central messages of this collection is that we are in for a surprise - there are no direct equivalents for these terms in, e.g., the language Yélî Dnye described below. Cognitive geographers have recently come to the same conclusions, calling for a systematic 'ethnophysiography' (Mark and Turk, 2003b, 2004). ${ }^{3}$ Since the surface of the earth is objectively a continuous surface (especially if we exclude water features), it can be segmented into quasi-objects in different ways - for example we can

\footnotetext{
${ }^{2}$ Cf. Cablitz, 2008.

${ }^{3}$ We should record our debt to David Mark, with whom we have been repeatedly in contact over the development of this project.
} 
conceive of a valley as a concave fold between mountain ranges, or as the flat bottom of such a fold, or as the entire drainage area right up the flanks, or do without any such concept. A dried up water course (or wadi) may be thought of as a river, but it consists only of the bottom and banks, which are perhaps not part of a river as English speakers think of it (see Mark and Turk, 2003a).

The variation in the ontology of labelable landforms across languages, as displayed in this volume, makes the point that landscape features do not come, for the most part, presegmented by nature. What then does determine the recognition of specific landform types as labelable entities in a language and culture? No one answer seems remotely adequate for the data gathered here. Perceptual salience sometimes seems to play only a minor role, while cultural and ecological preoccupations (e.g., subsistence pattern, symbolic significance, human affordance and hindrance) seem to have more profound influences. In other studies of human categorisation of the environment, for example in ethnobiology, there have been lively discussions about whether the categories are driven by a natural human intellectual interest or by utilitarian considerations (Berlin, 1992, versus Hunn, 1982, 1985; see also Malt, 1995). In the landscape domain, however, one might expect utilitarian factors to have predominance. It is therefore interesting to find a recurrent theme in the data in this collection: landscape terms tend to be organised around an imposed cognitive scheme or template, sometimes overt in the morphology, sometimes covert in the semantics. We explain this further below, under the rubric of semplates.

These ontological puzzles might seem to be of only academic interest, but nothing could be further from the truth. With the rise of geographic information systems and global positioning systems playing a central role in navigation, resource management, emergency services and the like, these ontological issues have come to have huge practical import. GoogleEarth, and its more sophisticated cousins, map place names all over the world - but in so doing they map indigenous names to an imposed universal ontology (of geographic entities like mountains, rivers, bays, etc. derived from an English conceptualisation of landscape reality). The local inhabitants may have something completely different in mind (on Rossel Island, for example, no river corresponds to a single name). When emergency aid is delivered, or a cruise missile for that matter, to the GIS label, it may be way off target, because of the potential underlying ontological mismatch. ${ }^{4}$

As this example makes clear, the Western tradition tends to think of place names as mapping to the ontology set up by our landscape terms: Mount Rossel should denote a mountain, Botany Bay should denote a bay, and The River Kwai should denote a river. But, as the paper on Jahai in this collection makes absolutely clear, this need not be the case: the terms for landscape features and the names for places can be hooked up to quite distinct ontologies. Place names are the one part of this field that have, of course, received a lot of traditional linguistic attention. Most of this attention derives from their historical interest, for place names are one of the most conservative elements in a language, surviving even repeated language shift (like Vienna from Celtic Vindobona through Latin into Germanic). They also form a universal, or near universal, linguistic category - and there are

\footnotetext{
${ }^{4}$ Moreover, current large-scale standardised mapping projects in developing countries may run counter to, and endanger, indigenous practices.
} 
not many such things. ${ }^{5}$ These facts point to some central cognitive utility that place names offer. Obviously, landscape terms tend to denote common recurring features of the landscape, making descriptive phrases of the kind the red cliffs potentially ambiguous. Above all, we have a great interest in the individuation of places, because that individuation makes talk about wayfinding possible, and further allows us to individuate human groups associated with places.

But utilitarian explanations of the importance of place names is partly beside the point, for places have a centrality in our cognition by ancient phylogenetic inheritance: in the midst of the vertebrate brain is an organ, the hippocampus, specialised in the memory for places. Birds that cache food over winter have bigger hippocampi than those who do not, and so do human taxi drivers over other city dwellers (Maguire et al., 2000). There are single cells in the hippocampus specialised for the memory of individual places (see Burgess et al., 1999). Moreover, there is a special brain system for distinguishing landmarks (places useful for wayfinding) from other kinds of places (Janzen and van Turennout, 2004). This specialised neural architecture was around millions of years before human language, just waiting for linguistic exploitation when humans finally got their act together and became language users. (Incidentally, the other major system of proper names, namely personal names, is also hooked to a specialised and ancient brain area for the recognition of individual conspecifics - see Enfield and Stivers, 2007).

What this specialised cognitive architecture provides is more than just quick, dedicated memory for places: it locates a place in a network of other places, for the hippocampus provides a mental map of the environment (O'Keefe and Nadel, 1978). It is this mental map that allows us to linguistically 'zoom in' and 'zoom out' - to vary the granularity of place description (see Schegloff, 1972). It is mental maps that give places their cognitive importance as waypoints in navigation. Mental maps also give places their general resonance in cognition, for example the art of memory is easily enhanced by hooking non-spatial memoranda to a spatial scheme (Yates, 1966). This resonance has been frequently noted in the anthropological record (see, e.g., Basso, 1996; Hercus et al., 2002; Levinson, 1996, etc.).

The intrinsic connection of places to other places, in a network forming a mental map, is precisely what is missing from traditional onomastics (the linguistics of names). Recently, Hunn (1996), Kari (1989) and others have suggested that place names deserve an investigation of precisely this sort, asking why some places get named, others not, why some cultures have dense systems of place names and others not, and whether the specific form of names (e.g., unanalysable versus transparent, uninomial versus binomial) reflects differing cognitive import. What the contents of this collection suggest, however, is that to spur a real science of place names we need to understand the landform ontologies that are often - though not always - deeply interconnected. We hope this special issue will partly achieve this.

To sum up so far: landscape constitutes an important, and relatively neglected, domain for linguistic exploration. It has deep cognitive underpinnings, and two major universal linguistic manifestations: landform terms, and place names. The dominant presumption has been that these two kinds of linguistic domain have universal, or near universal, onto-

\footnotetext{
${ }^{5}$ A possible exception is the village sign system Kata Kolok in Bali, which apparently lacks place names, using an absolute pointing system instead (Ulrike Zeshan, personal communication). We know of no other such reports.
} 
logical foundations. But it turns out that this is far from true, as established by Mark and Turk (2003a) and the papers in this collection.

\section{The cross-linguistic perspective}

The present collection of articles is the outcome of collaborative work carried out within the Space Project in the Language and Cognition Group at the Max Planck Institute for Psycholinguistics. Research has revolved around a set of questions first formulated in a questionnaire by Bohnemeyer (2001), later expanded by Bohnemeyer et al. (2004). Initially targeting the formal and functional properties of place names, the research agenda was widened to also incorporate the linguistic categorisation of the physical environment, as reflected in generic landscape terms. The general questions serving as guidelines for the research can be summarised as follows:

1. How is landscape divided into categories, and how are these categories named? Are there cross-linguistic differences in how landscape is divided into categories? Which are the main determinants of landscape categorisation?

2. How do we formally identify place names? What places are place names employed to refer to? How are places semantically construed for this purpose?

3. What is the denotational relation between landscape terms and place names?

Each contribution represents a detailed account of one or more of these issues in the context of a particular language (typically in traditional small-scale societies), written by one or more experts on the language in question and based on data from first-hand fieldwork. There are nine such contributions, representing a range of genetically, typologically and geographically diverse languages: Brown's on Tzeltal (Mayan, Mesoamerica), Burenhult's on Jahai (Mon-Khmer, Malay Peninsula), Cablitz's on Marquesan (Austronesian, Polynesia), Enfield's (2008) on Lao (Tai, Mainland Southeast Asia), Levinson's (2008) on Yélî Dnye (isolate, Island Melanesia), O’Connor and Kroefges's (2008) on Lowland Chontal (isolate, Mesoamerica), O’Meara and Bohnemeyer's on Seri (isolate, Mesoamerica), Senft's on Kilivila (Austronesian, Island Melanesia), and Widlok's on $\neq$ Akhoe Hai//om (Khoisan, southwestern Africa) (see Fig. 1).

Even in this small sample of languages, the cross-linguistic approach allows for a comparison of landscape terms and place names in (a) similar and different ecologies and (b) similar and different subsistence systems. For example, we are in a position to compare the categorial systems of unrelated languages in similar as well as varying ecologies. Also, we can compare systems used in similar subsistence situations but in unrelated languages and vastly different environments (see Sections 3.1, 3.2).

The comparison offers interesting insights into ontological diversity as well as constraints, and Sections 3.1-3.6 outline the most significant generalisations to be made from the present work.

\subsection{Carving out categories: cross-linguistic diversity}

Our language sample provides evidence of considerable cross-linguistic variation in terms of the denotational properties of landscape terms. Convex geomorphic features are one case in point. Comparing those terms for which the English gloss 'mountain' is 


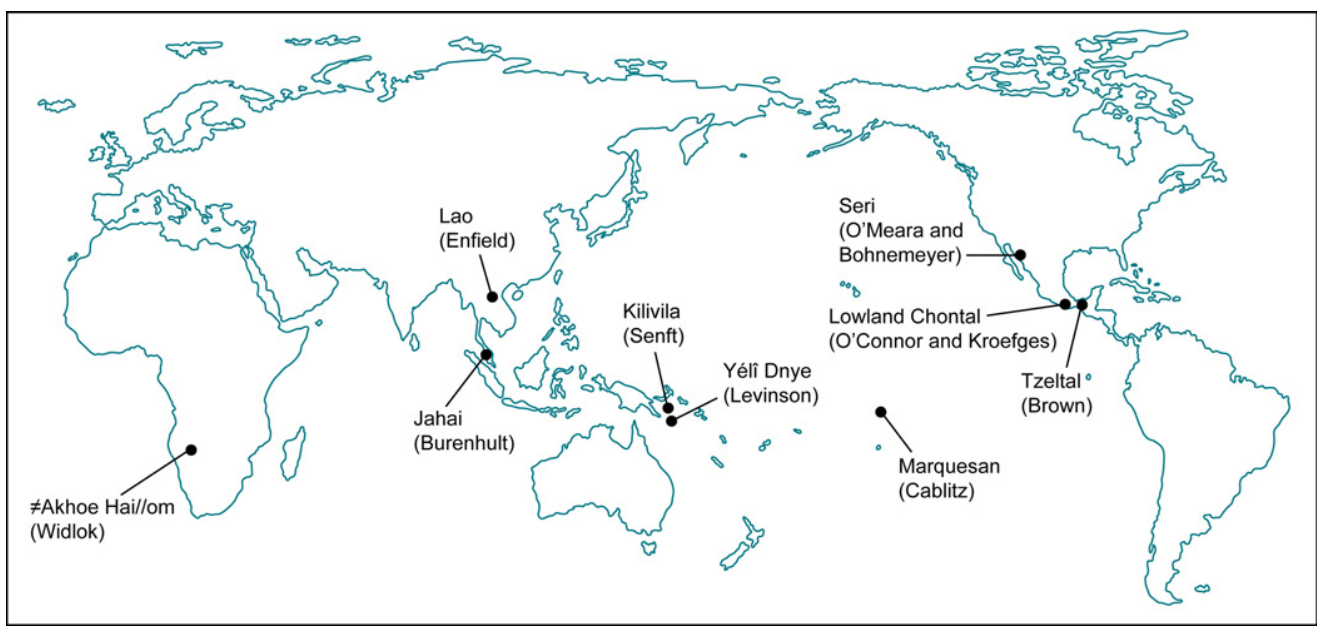

Fig. 1. Languages represented in this special issue.

used, we see some differences in denotation. The Yélî Dnye term $m b u$ is unspecified as to size, being applicable to features of varying magnitude (mountains, hills and even crab mounds on the beach), and only encodes that the feature has a conical shape. Similar non-specificity as to size is reported for Lowland Chontal ijwala', although this term is applicable only to real geomorphic features and not anthills, for example. Tzeltal witz similarly translates as both 'mountain' and 'hill', as does Kilivila koya. On the other hand, several mountain terms in Marquesan are all described as denoting large-scale convex features and categorising according to shape or location of the feature. Seri hast com is defined by its 'substance' (stone) and posture (lying). Lao phuu2, finally, is translated as 'mountainous terrain'. While this term encodes elevated landmass, it does not refer to a conical or similar unit.

When we turn to concave geomorphic features, it is interesting to note that a category corresponding to English 'valley' is not universally present in our sample. Kilivila, Lowland Chontal and Tzeltal are described as having a valley term comparable to that of English. The Marquesan term for valley is the same as that for river and village. Lao and Yélî Dnye lack a valley term, the closest equivalent terms meaning things like 'gradient' or 'bottom of inclined plane'. This absence of terminology cannot be explained by an absence of the landscape feature in question: both these languages are certainly spoken in environments containing features which would be referred to as valleys in English.

Running water is another example. Terms glossed as 'river' differ considerably as to what they denote. Some languages make no lexical distinction between water as a substance and water as a landscape feature (cf. Jahai). Some languages make a distinction based on size, Tzeltal and (to some extent) Lao being cases in point; others less so, like Lowland Chontal and Seri. Yélî Dnye segments running water into three distinct portions of a drainage system, two of which make up what would normally be translated as 'river' and one which falls outside the denotation of the English term (the flow of river water across a lagoon, between the river mouth and the reef opening). $\neq$ Akhoe Hai//om makes no distinction between permanent watercourses and dry riverbeds which only sporadically contain running water. 
The comparison of categorisation systems whose ecology is, in relevant respects, very similar also reveals marked differences. Kilivila and Yélî Dnye are unrelated but both spoken in similar marine ecologies in Island Melanesia. Both have rich sets of marine vocabulary denoting parts of the sea, based on the contour of the ocean floor between the beach and the deep sea outside the reef. Yet they segment this part of the environment in different ways (see the comparison made in Levinson's contribution; see also Senft, 2008).

Clearly, languages can differ considerably in the denotational properties of landscape terms, even for seemingly easily translatable terms. Different languages segment and outline landforms in different ways: while Yélî Dnye $m b u$, Lowland Chontal ijwala, Lao phuu2 and English mountain may all be used to refer to the same instance of raised sloping landmass, careful investigation of their extensional range reveals variation in semantic content. The 'valley' example also shows that features which might be thought of as obvious candidates for labelling need not find lexical expression in all languages. Here our results parallel those of Mark and Turk (2003a, 2004).

\subsection{Driving forces of categorisation}

Some contributions address the question of what it is that causes a language to categorise and label the geographical environment in a certain way. Three main hypotheses of category formation have here served as starting points: (1) the independent salience of features, (2) the interactional properties of features, especially their utilitarian significance to the speech community, and (3) cultural and linguistic models present in the speech community (outlined further in Section 3.4).

Brown and Levinson, describing Tzeltal and Yélî Dnye respectively, suggest that all three types of category formation come into play, although not in equal doses. Yélî Dnye, for example, is described as relying mainly on a cultural model, as well as utilitarian properties relating to subsistence and transport, but less on perceptual salience. Burenhult, describing Jahai hydrological terminology, argues that distinct systems of lexical categorisation can have different motivation. For example, one labelling system can pick out perceptually and interactionally salient features, whereas another system systematically avoids such features. In Seri, as described by O'Meara and Bohnemeyer, landscape categorisation is strongly determined by the tools provided by the structure of the language. Enfield's account of Lao focuses specifically on this issue: he argues that lexical categorisation at large cannot be directly explained by the natural or utilitarian salience of entities, but must be understood through the utility of words in conversation.

When we compare individual languages, it is clear that ecology is not a reliable predictor of how categorisations are made, as shown by the comparison of Kilivila and Yélî Dnye seascape terminology (see Section 3.1 and Levinson, 2008). In this case, independent salience of features does not help to produce the same categorial output in different languages. Similarly, the general subsistence system of a speech community is not necessarily a good indicator of the types of categorisations made in language. The three languages of our sample which are spoken in hunter-gatherer communities $-\neq$ Akhoe Hai//om, Jahai and Seri - show no evidence of sharing categorial strategies distinct from those of the other languages. On the contrary, any similarities tend to cross-cut the different modes of subsistence. For example, reliance on the body metaphor is a cat- 
egorial feature which Jahai shares with Marquesan and Tzeltal but not with its subsistence equals. The closest equivalent of the Seri strategy of categorisation is found in Lowland Chontal, spoken by an agricultural and trading community. In these cases, similar styles of interaction with landscape fail to produce similar categorisation in different languages. (Rather, the similarities between Seri and Lowland Chontal suggest that the typological characteristics of the language can be a significant factor in categorisation, although there is little further support for this in the rest of our sample.)

Clearly, however, the proposed driving forces of landscape categorisation are difficult to tease apart. Perceptual salience can be an interactional property; utilitarian significance is itself a manifestation of culture; cultural and linguistic models are likely to have utilitarian motivation or rewards, and they can set out from perceptually salient features (be it inside or outside the domain of landscape itself); and so on. Perhaps it is not so much a question of which driving force of categorisation is the most relevant one, but instead how the forces interact and from what levels of representation they operate.

\subsection{Landscape as a semantic domain}

Is landscape a cross-linguistically distinct and easily identifiable domain? European cultures identify categories like 'landscape' and 'geography', but are these to be treated on a par with reasonably well-established semantic domains like kinship, colour, anatomy and biology? Despite the points raised earlier about the neurocognitive basis and general linguistic ontology of places, our cross-cultural sample suggests there is reason to be cautious about the integrity of landscape, at least as far as generic terms are concerned. Unique beginner terms for landscape as a whole are not in much evidence, and no domain-encompassing systems of lexical relations are reported. Brown, for example, proposes the existence of a 'physical environment' domain in Tzeltal on the basis of structural evidence of object properties but shows that terms for such objects do not enter into lexical relations with each other and are not subsumed under an overarching landscape label.

Other contributions emphasise the inseparability of landscape from other domains. In his account of $\neq$ Akhoe Hai//om, Widlok tells of how notions of landscape are initimately intertwined with notions of settlement, migration, resources and ethnicity, suggesting that landscape is indeed an artificial domain. Cablitz's account of Marquesan suggests that landscape features are not straightforwardly separable from atmospheric and celestial features. Moreover, Burenhult's contribution on Jahai suggests that mapping of the physical environment can be secondary in the sense that it largely draws on other domains, thereby ruling out landscape as itself representing a distinct and basic domain.

This reinforces the picture of the physical environment as being a setting or scene onto which linguistic categorisation can operate in a multitude of ways, both within and across languages. It is less of an independent backdrop in the form of a discrete and self-standing categorial system (again, see Widlok, 2008). Arguably, landscape is therefore qualitatively very different from semantic domains like kinship, anatomy and life forms. Indeed, such domains are sometimes employed to map landscape, among other things. However, lexical subsystems of a different sort do seem to make landscape their major locus operandi, as will be shown in the following section, and these systems suggest that landscape may form a coherent domain in at least some languages. 


\subsection{Language and culture shape the land: leitmotifs and semplates}

A significant finding emerging from the work presented in this special issue is that the geographical environment can lend itself to categorisation according to prefabricated cultural or linguistic systems. Several accounts report a 'design principle' (O'Meara and Bohnemeyer, 2008), 'template', 'model', 'schema' or 'frame' (Brown, 2008; Burenhult, 2008; Cablitz, 2008; Levinson, 2008), which helps to organise the landscape domain categorically. Specifically, cultural themes or linguistic patterns are imposed on the environment to create, co-ordinate, subcategorise, or contrast landscape categories. ${ }^{6}$

Such systems vary in how they surface linguistically and are not always easy to discern. For example, the lexical instantiations of the 'up/down/across' model described for Yélî Dnye provide few clues as to wider semantic relations, yet underlyingly there is a consistent pattern of oppositions which pervades much of the landscape-related terminology as well as place-naming. ${ }^{7}$

Lexically more overt systems are those employing metaphor to map landscape features (see especially the accounts of Jahai, Marquesan and Tzeltal). Such systems draw on source domains like body and kinship to create partonymic and taxonomic relationships within and between landscape categories, sometimes abstracting away from the individual features themselves to a point where the semantic content of labels becomes restricted to a minimum (see Burenhult's contribution). So, while the system is lexically instantiated and thus easy to identify and characterise linguistically, its exact denotational relationship to the landscape features it labels is harder to pin down. Importantly, such mapping systems rooted in domains outside landscape can be pervasive in mapping the physical domain as a whole, not just geographical features.

The typological design principle proposed by O'Meara and Bohnemeyer for Seri exemplifies yet another type of system. Here, an overarching typological feature of the language provides the tools for landscape categorisation, effectively creating objects from a basic set of 'elements' (seawater, freshwater, stone, and land) according to a pattern common to the whole nominal lexicon. A similar interpretation is given to Lowland Chontal by O'Connor and Kroefges, but with the added notion of basic materials like water and earth (described as 'primary forces of nature') as agents, doers or causers of landscape, as reflected in a large portion of the landscape lexicon.

Another possible example of such a cultural template is the salient inside-outside dichotomy described by Cablitz for parts of the Marquesan system of categorisation.

As is evident, these ontological systems set out from different conceptual baselines, or leitmotifs. Motion drives the model in Yélî Dnye; part and size (and ultimately animacy) are the dimensions expressed by the metaphorical templates in Jahai, Marquesan and Tzeltal; agency shapes the system in Lowland Chontal; substance forms the running theme in Seri; and containment catches the essence of the Marquesan example. One can imagine other such fundamental themes, not found in the present sample. Furthermore, languages can make use of more than one leitmotif, as shown by Jahai and Marquesan, where separate templates of motion, part and size, and part and containment, respectively, provide alternative ontologies.

\footnotetext{
${ }^{6}$ For similar phenomena reported elsewhere, see e.g. Bennardo, 2002, 2005; Gell, 1995; Gow, 1995; WazirJahan, 1980.

${ }^{7}$ Cf. Whorf's so-called cryptotypes (Whorf, 1945, 1964).
} 
While different in terms of what constitutes the leitmotif and how the mapping finds lexical expression, the various systems are similar in that all represent semantic generalisations which do not restrict themselves to single semantic domains or fields. Together they form a level of representation which does not find any clear equivalent in existing semantic theory, and we here propose the term 'semplates' (a blend of 'semantic templates') as a generic label for them. Arguably, such semplates are potentially significant as engines in the structuring of native conception and lexicon.

Semplates have interesting connections to the 'cultural models' of psychological anthropology (Holland and Quinn, 1987; D’Andrade and Strauss, 1994). Cultural models are culturally formed cognitive schemas which determine how human reality is constructed and interpreted in thought and action. Semplates would seem to represent a linguistic counterpart of such models and may indeed be linguistic manifestations of them, at least in some cases. The exact relationship between semplates and cultural models promises to be an interesting area for future research. But a more immediate (and prerequisite) future concern for linguists is to explore and establish more firmly the characteristics and role of semplates in language, both in landscape and elsewhere.

\subsection{Naming principles: how to generate place names}

In our sample, the linguistic characteristics of place names vary in the following dimensions: degree of semantic analysability, morphological complexity, syntactic identity, and the lexical source domains from which names are drawn (including reliance on landscape terms).

In the absence of etymology, the semantic analysis of place names is fraught with danger. Consultants' explanations of the meaning of names are, at least in non-straightforward cases, highly likely to be folk etymologies having little to do with historical reality. Such folk etymologies can represent conventions upheld by the whole speech community, or they can be made up on the spot. While of considerable interest in their own right, they are not necessarily very informative about the strategies once used to create the names. It is therefore important, although not always easy, to maintain a distinction between names which are semantically analysable and those which are not. Contributions to this special issue differ in their reporting as to the extent of such analysability. While the accounts of Lowland Chontal and Marquesan tell of a high degree of semantic transparency in place names, those of $\neq$ Akhoe Hai//om, Jahai, Kilivila, Tzeltal, and Yélî Dnye suggest a more or less substantial component of semantically opaque names (for which there may nevertheless be elaborate folk etymologies, cf. Jahai and Kilivila). Possibly, such differences in degree of analysability have historical roots, reflecting for example varying antiquity of a language in its region (long linguistic continuity being associated with archaisms in place names), or differences in willingness to adopt place names of previous linguistic strata or borrow them from neighbouring languages.

The languages also differ somewhat as to the degree of morphological complexity in place names. Jahai is radical in having almost only simplex (monomorphemic) forms, Lowland Chontal shows a preference for complex (binomial) forms, and Kilivila, Marquesan, Tzeltal, and Yélî Dnye display a mix of forms. This relates to which syntactic units a language allows itself to use as place names. While Jahai place names, to the extent that they are semantically transparent, are typically bare nouns (e.g., 'Axe', 'Cartridge', 'Eagle'), many place names in $\neq$ Akhoe Hai//om, Kilivila, Lowland Chontal, Marquesan 
and Tzeltal are nominal compounds (e.g., 'Flower Rock', 'Birds' Island', 'Cross Cave') or otherwise modified nouns ('Mad People', 'Difficult Point', 'Big Mouth'). Marquesan names are frequently nouns with a definite article ('The Coconut', 'The Forehead'). Kilivila and Marquesan have examples of place names in the form of adpositional phrases ('Towards the Almond Tree', 'Above the Bird'). Occasionally, place names are represented by whole clauses or exclamations.

Most of the languages show great internal variation with respect to the lexical source domains from which place name components are drawn. Terms representing landscape features, body parts, animals, plants, objects, people, proper names, properties, and activities all feature more or less prominently. Of particular interest to us, however, is that languages appear to differ considerably as to the extent to which they make use of landscape terms in creating place names. Jahai and Yélî Dnye represent extremes in this regard, the latter making frequent use of them, the former not at all. An example of a distinction within the class of landscape terms is provided by Lowland Chontal, where place-naming frequently involves landscape terms denoting geographic objects but never terms derived from the words denoting the substances of water and earth.

A mythical and/or commemorative dimension is evident in many of the systems described, see especially the accounts of Jahai, Kilivila, Lowland Chontal, Marquesan and Tzeltal.

\subsection{What gets named?}

The denotational properties of place names point to interesting cross-cultural differences in how place names form systems and how such systems are anchored in the landscape. One potentially significant distinction to explore is that between feature names and area names. We define feature names as place names which individuate and denote identifiable features of concrete geography, such as landforms (mountains, rivers, caves etc., e.g., Snowdon, Rhine), human-made entities (settlements, roads, garden plots, bridges, etc., e.g., Amsterdam, The Appalachian Trail, Golden Gate), and biological entities (stands of vegetation, individual trees, animal dwellings etc., e.g., Major Oak in Sherwood Forest and The Senate, a group of giant sequoias in Sequoia National Park, California). Feature names have the potential to pick out a whole range of divergent aspects of the natural and constructed environment and name them in close symbiosis with generic linguistic categories referring to concrete geographic features, such as landscape terms, but they are unable to provide total coverage of the environment. Area names, on the other hand, can be defined as place names which individuate and denote regions not naturally given by concrete geography, such as units or tracts of land defined by ownership, usage rights, political/administrative influence, ethnicity, kinship, history, myth, or other conceptual associations (e.g., Soho, Orange County, Languedoc). Area names have the potential to totally cover the environment in a patchwork of named units, but cannot distinguish individual concrete features and consequently do not have co-referential relationships with generic linguistic categories referring to such features. Area names may well form overlapping sets, with or without common boundaries. ${ }^{8}$

\footnotetext{
${ }^{8}$ Incidentally, as will be shown below, these differences between feature names and area names hold even though area names may often be drawn metonymically from feature names.
} 
While we can assume that most languages probably make use of both feature names and area names, it is interesting to note cross-linguistic differences in the balance between the two. In our sample, Yélî Dnye stands out as making the most systematic use of both strategies (much like what could be claimed for European languages). A mix of systems is evident also in Tzeltal; here feature-naming has a connection to indigenous names, while some area names (of an administrative nature) are frequently forms borrowed from colonial Spanish. Kilivila, Marquesan and Lowland Chontal all seem to have a clear bias towards feature names. $\neq$ Akhoe Hai//om provides examples of what would seem to be a flexible system of feature names which are productively 'stretched' according to need to become area names. $\neq$ Akhoe Hai//om also has names for larger regions which are based on dominating landscape features but which abstract away from those features, associate with activity and ethnicity, and, in effect, become area names. Jahai, finally, can be argued to systematically use only area names. While anchored in drainage, Jahai place names operate independently of generically labelled landscape categories and effectively cover the territory in named units. However, the papers in this collection do not claim to include an exhaustive (or even a truly representative) sample of place names for each language, so conclusions here can only be tentative.

Looking at the relationship between what is named and how it is named, we find that feature names predictably often include the generic terms for the feature in question and are then descriptive in character (e.g., Marquesan 'Birds' Island', Tzeltal 'Treemoss Mountain', Yélî Dnye 'Snake Passage'). Area names are less inclined to draw on such feature terms; Jahai names, for example, never consist of or include generic terms referring to local features. But there are exceptions: features can give their names to whole areas, as in the case of $\neq$ Akhoe Hai//om. This is a strategy which is also found in Lowland Chontal and Tzeltal (e.g., three peaks giving the name 'Three Mountains' to a whole traditional area). Conversely, Kilivila names show a very close association denotationally with landscape features but seldom include the generic terms for those features.

Another dimension worthy of further investigation is the role of hierarchy in placenaming (cf. Basso, 1984). Can referents of named places be described as being organised into neat partonymies, with smaller entities nestled in larger ones? And are there restrictions as to the number of levels? Again, the distinction between feature names and area names may be helpful in outlining the various possibilities available. Feature names have the potential to form hierarchies with other feature names (say, for example, rock $\mathrm{X}$ as part of mountain Y), and area names with other area names (e.g., the two-level system proposed for Jahai). But feature names may also subcategorise under area names (the overlapping systems in Yélî Dnye may be a case in point), and area names can potentially refer to parts of a larger entity associated with a feature name (e.g., individually named conceptual units on the slopes of a named mountain). Are there languages which avoid hierarchy altogether, preferring instead to organise named places into associative networks based on, e.g., spatial proximity or contiguity, or more abstract associations (myth, kinship, etc.)? Some aspects of the system described for $\neq$ Akhoe Hai//om are reminiscent of this. And are there languages which simply do not bother to organise place names at all in relation to each other? In the absence of structural evidence, these issues are difficult to untangle, and the cross-linguistic tendencies are therefore still unclear.

A related issue is how named places are crossed with generic categories to yield specific reference. For example, can referents of place names be productively subcategorised by means of spatial relator expressions like 'top', 'side' and 'bottom', as in Tzeltal? Or by 
means of metaphorical systems drawing on, e.g., body part terms? Another possibility is that place names combine productively with, e.g., landscape terms to create unique reference. This is a strategy employed consistently in Jahai by means of associative phrases, and with possessive constructions in Tzeltal for reference to rivers and trails.

\section{Conclusion}

The contributions to this special issue explore the linguistic categories of landscape terms and place names in a range of diverse languages. While these two kinds of categories are universal (or near universal), the data presented here provides evidence of considerable variation within and across languages in how each of them is ontologised. Systems vary as to how categories are carved out and what it is that drives this categorisation, how place names are generated and what entities receive such names. Landscape, it turns out, does not automatically give you an ontology - there is a great deal of plasticity in how language models the earth and in what is considered to be the essence of its features. Capturing landscape ontology cross-culturally is about understanding this variation, identifying limits to it, and exploring the balance within and across languages. The variation in underlying ontology is a matter of great practical importance, as understanding the correct reference of landscape terms and place names is essential to many major areas of human joint endeavour, from mapping to international law. We also hope to have shown that landscape is a linguistic domain of considerable interest in its own right and one that provokes questions of general significance to language science.

\section{Acknowledgements}

We are grateful to the following people for their helpful input: Melissa Bowerman, Penny Brown, Gaby Cablitz, Nick Enfield, Clair Hill, Asifa Majid, Loretta O'Connor, Carolyn O’Meara, Gunter Senft and Thomas Widlok. Special thanks are directed to David Mark and Andrew Turk for their unstinting interest in and support of this whole comparative project and for their careful examination of this paper. We also thank Ludy Cilissen, Alex Dukers and Tilman Harpe for their assistance in preparing many of the images.

\section{References}

Basso, K.H., 1984. Western Apache Place-Name Hierarchies. In: Tooker, E. (Ed.), Naming Systems. American Ethnological Society, Washington, DC, pp. 78-94.

Basso, K.H., 1996. Wisdom Sits in Places: Landscape and Language Among the Western Apache. University of New Mexico Press, Albuquerque.

Bender, B. (Ed.), 1993. Landscape: Politics and Perspectives. Berg, Providence.

Bennardo, G., 2002. Mental Images of the Familiar: Cultural Strategies of Spatial Representation in Tonga. In: Bennardo, G. (Ed.), Representing Space in Oceania: Culture in Language and Mind. Pacific Linguistics, Canberra, pp. 159-177.

Bennardo, G., 2005. Radiality in Tongan Production About Social Relations. Paper Presented to the American Anthropological Association, Washington, DC, December 4, 2005.

Berlin, B., 1992. Ethnobiological Classification: Principles of Categorization of Plants and Animals in Traditional Societies. Princeton University Press, Princeton.

Bohnemeyer, J., 2001. Toponym Questionnaire. In: Levinson, S.C., Enfield, N.J. (Eds.), 'Manual' for the Field Season 2001. Max Planck Institute for Psycholinguistics, Nijmegen, pp. 55-61. 
Bohnemeyer, J., Burenhult, N., Enfield, N.J., Levinson, S.C., 2004. Landscape Terms and Place Names Elicitation Guide. In: Majid, A. (Ed.), . In: Field Manual, vol. 9. Max Planck Institute for Psycholinguistics, Nijmegen, pp. 75-79.

Brown, P., 2008. Up, down, and across the land: landscape terms, place names, and spatial language in Tzeltal. Language Sciences 30, 151-181.

Burenhult, N., 2008. Streams of words: hydrological lexicon in Jahai. Language Sciences 30, 182-199.

Burgess, N., Jeffery, K., O'Keefe, J., 1999. The Hippocampal and Parietal Foundations of Spatial Cognition. Oxford University Press, Oxford.

Cablitz, G.H., 2008. When "what" is "where": a linguistic analysis of landscape terms, place names and body part terms in Marquesan (Oceanic, French Polynesia). Language Sciences 30, 200-226.

D’Andrade, R., Strauss, C. (Eds.), 1994. Human Motives and Cultural Models. Cambridge University Press, Cambridge (Publications of the Society for Psychological Anthropology).

Ellen, R.F., Fukui, K. (Eds.), 1996. Redefining Nature: Ecology, Culture and Domestication. Berg, Oxford/ Washington, DC.

Enfield, N.J., 2008. Linguistic categories and their utilities: the case of Lao landscape terms. Language Sciences $30,227-255$.

Enfield, N.J., Stivers, T. (Eds.), in press, 2007. Person Reference in Interaction: Linguistic, Cultural, and Social Perspectives. Cambridge University Press, Cambridge.

Gell, A., 1995. The Language of the Forest: Landscape and Phonological Iconism in Umeda. In: Hirsch, E., O'Hanlon, M. (Eds.), The Anthropology of Landscape: Perspectives on Place and Space. Clarendon Press, Oxford, pp. 232-254.

Gow, P., 1995. Land, People, and Paper in Western Amazonia. In: Hirsch, E., O’Hanlon, M. (Eds.), The Anthropology of Landscape: Perspectives on Place and Space. Clarendon Press, Oxford, pp. 43-62.

Hercus, L., Hodges, F., Simpson, J. (Eds.), 2002. The Land Is a Map: Placenames of Indigenous Origin in Australia. Pandanus Books, Canberra.

Hirsch, E., O'Hanlon, M. (Eds.), 1995. The Anthropology of Landscape: Perspectives on Place and Space. Clarendon Press, Oxford.

Holland, D.C., Quinn, N. (Eds.), 1987. Cultural Models in Language and Thought. Cambridge University Press, Cambridge.

Hunn, E., 1982. The Utilitarian Factor in Folk Biological Classification. American Anthropologist 84, 830-847.

Hunn, E., 1985. The Utilitarian Factor in Folk Biological Classification. In: Dougherty, J.W.D. (Ed.), Directions in Cognitive Anthropology. University of Illinois Press, Urbana, pp. 117-140.

Hunn, E., 1996. Columbia plateau Indian place names: What can they teach us? Journal of Linguistic Anthropology 6, 3-26.

Jackendoff, R., 1983. Semantics and Cognition. MIT Press, Cambridge, MA.

Janzen, G., van Turennout, M.I., 2004. Selective neural representation of objects relevant for navigation. Nature Neuroscience 7, 673-677.

Kari, J., 1989. Some Principles of Alaskan Athabaskan Toponymic Knowledge. In: Kay, M.R., Hoenigswald, H.M. (Eds.), General and Amerindian Ethnolinguistics: In Remembrance of Stanley Newman. Mouton de Gruyter, New York, pp. 129-149.

Landau, B., Jackendoff, R., 1993. "What" and "where" in spatial language and spatial cognition. Behavioral and Brain Sciences 16, 217-265.

Levinson, S.C., 1996. Language and space. Annual Review of Anthropology 25, 353-382.

Levinson, S.C., 2003. Space in Language and Cognition: Explorations in Cognitive Diversity. Cambridge University Press, Cambridge.

Levinson, S.C., 2008. Landscape, seascape and the ontology of places on Rossel Island, Papua New Guinea. Language Sciences 30, 256-290.

Lyons, J., 1977. Semantics, Vols. I and II. Cambridge University Press, Cambridge.

Maguire, E., Gadian, D., Johnsrude, I., Good, C., Ashburner, J., Frackowiak, R., Frith, C., 2000. Navigationrelated structural change in the hippocampi of taxi drivers. Proceedings of the National Academy of Sciences 97 (8), 4398-4403.

Majid, A., Bowerman, M., Kita, S., Haun, D.M.B., Levinson, S.C., 2004. Can language restructure cognition? The case for space. Trends in Cognitive Sciences 8 (3), 108-114.

Majid, A., Enfield, N.J., van Staden, M. (Eds.), 2006. Cross-Linguistic Categorization of the Body. Language Sciences 28.

Malt, B.C., 1995. Category coherence in cross-cultural perspective. Cognitive Psychology 29, 85-148. 
Mark, D.M., Turk, A.G., 2003a. Landscape Categories in Yindjibarndi: Ontology, Environment, and Language. In: Kuhn, W., Worboys, M., Timpf, S. (Eds.), Spatial Information Theory: Foundations of Geographic Information Science, In: Lecture Notes in Computer Science 2825. Springer-Verlag, Berlin, pp. 28-45.

Mark, D.M., Turk, A.G., 2003b. Ethnophysiography. Paper presented at Workshop on Spatial and Geographic Ontologies, September 23, 2003, (prior to COSIT03).

Mark, D.M., Turk, A.G., 2004. Ethnophysiography and the ontology of landscape. Proceedings of GIScience, $152-155$.

Mark, D.M., Smith, B., Tversky, B., 1999. Ontology and Geographic Objects: An Empirical Study of Cognitive Categorization. In: Freksa, C., Mark, D.M. (Eds.), Spatial Information Theory: Cognitive and Computational Foundations of Geographic Information Science, In: Lecture Notes in Computer Science 1661. Springer-Verlag, Berlin, pp. 283-298.

O'Connor, L., Kroefges, P.C., 2008. The land remembers: landscape terms and place names in Lowland Chontal of Oaxaca, Mexico. Language Sciences 30, 291-315.

O’Meara, C., Bohnemeyer, J., 2008. Complex landscape terms in Seri. Language Sciences 30, 312-335.

O'Keefe, J., Nadel, L., 1978. The Hippocampus as a Cognitive Map. Clarendon Press, Oxford.

Piaget, J., Inhelder, B., 1971 [1948]. The Child's Conception of Space. Routledge and Kegan Paul, London.

Schegloff, E.A., 1972. Notes on a Conversational Practice: Formulating Place. In: Sudnow, D. (Ed.), Studies in Social Interaction. Free Press, New York, pp. 75-119.

Senft, G., 2008. Landscape terms and place names in the Trobriand Islands - the Kaile'una subset. Language Sciences 30, 336-357.

Smith, B., Mark, D.M., 2001. Geographical categories: An ontological investigation. International Journal of Geographical Information Science 15 (7), 591-612.

Smith, B., Mark, D.M., 2003. Do mountains exist? Towards an ontology of landforms. Environment \& Planning B: Planning \& Design 30 (3), 411-427.

Tilley, C., 1994. A Phenomenology of Landscape: Places, Paths and Monuments. Berg, Oxford.

Wazir-Jahan, K., 1980. Introduction to the Ma' Betisek of Peninsular Malaysia. Federation Museums Journal 25, $119-158$.

Whorf, B.L., 1945. Grammatical categories. Language 21, 1-11.

Whorf, B.L., 1964 [1956]. A Linguistic Consideration of Thinking in Primitive Communities. In: Carroll, J.B., (Ed.), Language, Thought and Reality: Selected Writings of Benjamin Lee Whorf. The MIT Press, Cambridge, MA, pp. 65-86.

Widlok, T., 2008. Landscape unbounded: space, place, and orientation in $\neq$ Akhoe Hai//om and beyond. Language Sciences 30, 358-376.

Yates, F.A., 1966. The Art of Memory. The University of Chicago Press, Chicago. 